Ankara Ecz. Fak. Der.

15,43 (1985)
J. Fac. Pharm. Ankara

15, 43 (1985)

\title{
Barbitüratların Ekstraktif Alkillenmeleri ve Gaz Kromatografik Tayinleri
}

\author{
Extractive Alkylation of Barbiturates and Their Determi-
} nation by Gas Chromatography

\section{Tülin SÖYLEMEZOĞLU*}

\section{ÖZET}

Bu çalışmada, toksikolojik analizlerde uygulanmak üzere, barbitüratlarm gaz kromatografisinde ekstraktif alkilleme ile analizleri için yöntem geliştirilmiştir. Ele alınan 12 barbitüratın ekstraktif alkilleme ile pentafluorobenzil türevleri oluşturulmuş, uygun gaz kromatografik kolon ve iç standart seçimi amacıyla değişik durucu fazlarda, alıkonma indeksleri bulunmuştur. Pentafluorobenzil türevleri için en duyarlı detektör; elektron yakalayan detektördür. SE-30 ise en hızlı sonuç alman gaz sıvı kromatografik durucu fazdır. Barbitüratlarm ekstraktif alkillenme hizları, tetrabutilamonyum konsantrasyonu ve pH değerlerine karşı araştırılmıştır. Barbitüratların ekstraktif alkillenmeleri için en uygun pH 9 olarak bulunmuştur. Reaksiyon ortamdaki tetrabutilamonyum konsantrasyonu $0.2 \mathrm{M}$ olduğunda 10 dakika içinde tamamlanmaktadır. Gaz kromatografik analizlerde elektron yakalayan detektör kullanıldığında saptanabilen en düşük madde miktar1 1 pikogram/ $\mu 1$ dir.

\section{SUMMARY}

In this research, a new method for barbiturates was developed which is applicable to toxicological analysis based on extractive alkylation and gas chromatography. The pentafluorobenzyl derivatives of twelwe barbiturates were prepared and their retention indices were 
PFBBr'le olduğu gibi metil iyodür gibi daha basit yapıdaki alkilleme reaktifleri ile de yürütülebilen ekstraktif alkillemenin diğer türevleme determined and compared with these of corresponding barbiturates on different gas chromatographic stationary phases. Electron-capture detector is the most sensitive for the pentafluorobenzil derivatives and the gas-liquid chromatographic stationary phase SE-30 gave the most rapid results. The rate of extractive alkylation of barbiturates was studied with respect to the concentration of tetrabutylammonium and $\mathrm{pH}$. Optimal $\mathrm{pH}$ for extractive alkylation of barbiturates was found to be 9 . The reaction was completed rapidly when the tetrabutylammonium concentration was $0.2 \mathrm{M}$. The minimum detectable quantity of PFB derivatives of barbiturates was found to be 1 picogram/ $\mu$ lusing ECD by gas chromatography.

Anahtar Kelimeler: (Barbitüratlar, Ekstraktif alkilleme, Gaz kromatografik analiz).

Barbitüratlar yaygın kullanım alanı olan sedatifve hipnotik ilaçlardır. Kazai zehirlenmelerde ve intihar olaylarında birinci sırada yer almaları $(1,2)$ ve bağımlılık yapan ilaçlardan oluşları nedeniyle toksikolojik analizler açısından önem taşırlar. Toksikolojik analizlerde en yaygın uygulanan yöntemlerden birisi olan gaz kromatografisinin barbitüratlar için uygulanabilirliğinin ancak türevleme işleminden sonra söz konusu olabileceği düşünülmektedir (3). Barbitüratların gaz kromatografik ayrımı sırasında hidrojen bağları nedeniyle kromatografik kolonda tutulmaları sonucu duyarlık düşmekte, kuyruklu pikler elde edilmektedir (4). Ayrıca alıkonma süresinin de miktara bağlı olarak değişmesi nicel ve nitel analizlerin yeterince doğru sonuçlar vermemesine neden olmaktadır (3). Genellikle gaz kromatografik koşullara uygun ve daha duyarlı türevler hazırlamak amacıyla barbitüratların alkillenmesi yoluna gidilmektedir. Bu türevlerin serbest asitlerden daha az polar olmalar nedeniyle gaz kromatografisinde durucu faz üzerinde ayrılmaları kolaylaşmaktadır (3). Diğer taraftan elektron yakalama özelliği daha fazla olan halojenli alkil türevleri duyarlığın elektron yakalayan detektörle (ECD), pikogram düzeyine inmesini sağlamaktadır. Türevlerin ve reaktifin dayanıklılığı, sulu ortamda çalışılabilme olanağı ve elde edilen türevlerin diğer halojenli türevlerden daha fazla duyarlıkta oluşu pentafluorobenzil bromürün (PFBBr) yeğlenen bir reaktif olmasına yol açmaktadır $(5,6)$. 
Barbitüratların Ekstraktif Alkillenmeleri ve Gaz.

reaksiyonlarına üstünlüğü ise, basit bir yöntem oluşu, kullanılan reaktiflerin tehlikesizliği, bazla katalizlenen diğer alkilleme yöntemlerine göre daha hızlı yürümesi ve çoğunlukla ekstraksiyon işlemi ile türevlemenin bir arada yürütülebilmesidir (7). PFBBr, barbitüratların alkilenmesi için ilk kez WALLE (8) tarafından, baz katalisti olarak trietilamin ve potasyum karbonat varlığında kullanılmıştır. GYLLEN HAAL ve arkadaşları (9) ise, PFBBr'le ekstraktif alkilleme işlemini, karşıt iyon olarak tetrabutilamonyum iyonunu (TBA) kullanarak fenobarbitale uygulamışlardır.

Biz toksikolojik analizlere uygulamak amaciyla ekstraktif alkilleme yöntemini, barbitüratların gaz kromatografik analizleri için geliştirmeyi uygun gördük.

Ekstraktif alkilleme işlemi ilk kez organik kimyada uygulanmasından (10) sonra çeşitli ilaç gruplarının biyolojik materyalden duyarlı olarak saptanması amacıyla birçok araştırıcı tarafından kullanılan bir yöntemdir. Yöntemin teorisi ve reaksiyonun yürüme mekanizması ayrıntılı olarak açıklanmıştır (11-16).

\section{DENEY KISIM}

\section{Materyal:}

Kimyasal Bileşikler: Barbitürat standartları yazılan ilaç firmalarından sağlanmıştır; Allobarbital (Atabay), Aprobarbital (F. Hoffmann-La Roche, isviçre), Barbital sodyum (Aarhus-Danimarka), Butalbital (Sandoz, isviçre), Butobarbital (Abbott, ABD), Fenobarbital sodyum (BDH, İngiltere), Heksobarbital (Siegfield, İsviçre), Heptabarbital (Ciba-Geigy, İsviçre), Pentobarbital sodyum (Abbott, ABD), Sekobarbital sodyum (E.Lilly, ABD), Siklobarbital kalsiyum (Wintrop, ABD), Vinbarbital (Astra, İsveç), çözücü ve kimyasal maddeler ise analitik niteliktedir.

Çözeltiler: TBA çözeltisi; $\mathrm{TBAHSO}_{4}{ }^{\prime} 1 \mathrm{n}$ fosfat tamponu ile değişik pH değerlerine ayarlanmasıyla hazırlanarak GLC-ECD çalışmaları için önce diklormetan sonra da distillenmiş n-heptanla yıkand1. Barbitürat stok çözeltileri; mililitrede $250 \mu g$ olacak şekilde suda, alkan standartları; ml de $100 \mu \mathrm{g}$ olacak şekilde $\mathrm{n}$-hekzanda hazırlandı. $0.5 \mathrm{M}$ hordenin sülfat; $0.1 \mathrm{M} \mathrm{NaOH}$ içinde hazırlandı. 
Fosfat tamponlarını hazırlamak için 0.1 M monosodyum hidrojen fosfat, 0.1 M disodyumhidrojen fosfat ve $0.1 \mathrm{M}$ trisodyum fosfat çözeltileri kullanıldı.

\section{Metod:}

Gaz Kromatografik Koşullar: Packard Becker 419 Gas Chromatograph'da alev iyonlaşma detektörü (FID) ve elektron yakalayan detektörle (ECD) çalışıldı. \% 3 OV-17 ve \% 3 SE-30 (Chromosorb W HP 100-120 mesh üzerinde) ile doldurulmuş $2 \mathrm{mx} 4 \mathrm{~mm}$ lik cam kolonlar kullanıldı. Kolon sicaklığ $1230^{\circ} \mathrm{C}-245^{\circ} \mathrm{C}$ arasına, detektör ve enjeksiyon giriş sıcaklıkları $260^{\circ} \mathrm{C}$ ye ayarlandı. Gaz akış hızları; azot $30 \mathrm{ml} /$ dakika, hidrojen $30 \mathrm{ml} /$ dakika, hava $250 \mathrm{ml} / \mathrm{daki}-$ kaya, duyarlık düzeyine göre (elektrometre alanı) x (attenuation) FID için; $10 \times 16$, ECD için; $2.5 \times 10^{-11}$ Ax216 veya 512 ye ayarlandı. Kağıt hızı dakikada $0.5 \mathrm{~cm}$ dir.

Alıkonma Índeksi Hesapları: Barbitüratların PFB türevlerinin alıkonma indeksleri LEACH'ın (17) verdiği, Şekil 3 de görülen formülden yararlanılarak hesaplandi. Bu formülde RI: alıkonma indeksi, Rd: alıkonma uzaklığının logaritması, Rd( $\mathrm{Pz})$ : küçük numaralı alkanın alıkonma uzaklığının logaritması, $\mathrm{Rd}(\mathrm{Pz}-\mathrm{n})$ : büyük numaralı alkanın alıkonma uzaklığının logaritması, z: küçük numaralı alkandaki karbon sayısı, n: iki alkanın karbon sayıları arasındaki farktir.

Ekstraktif Alkilleme İşlemi: Bu amaçla GYLLENHAAL ve arkadaşlarının (9) kullandığı yöntem değiştirilerek uygulandı. Ekstraktif alkillemede pH'nın reaksiyona etkisini saptamak amaciyla konik dipli santrifüj tüpüne $0.2 \mathrm{ml}(125 \mu \mathrm{g} / \mathrm{ml})$ barbitürat çözeltisi kondu, üzerine değişik pH larda hazırlanmış $0.4 \mathrm{ml} 0.5$ M T B A çözeltisi ilave edildi, $0.4 \mathrm{ml}$ uygun $\mathrm{pH}$ da fosfat tamponu, $0.5 \mathrm{ml}$ diklormetan ve $10 \mu 1 \mathrm{PFBBr}$ ilavesinden sonra çalkalayıcı da 10 dakika çalkalandı. Üstten sulu faz alınıp diklormetan fazı azot akımında uçurulduktan sonra kalıntı iç standart olarak $0.1 \mathrm{mg} / \mathrm{ml}$ tetrakozan veya hekzakozan taşıyan $0.5 \mathrm{ml}$ n-hekzanda 2 dakika çalkalanarak çözüldü. Barbitüratlardan her biri için bu aşamada kullanılan iç standartlar tablo 4'de gösterilmiştir. Bu çözeltiden $1 \mu$ gaz kromatografa enjekte edilerek barbitürat $P F B$ türevlerinin iç standart pik yüksekliklerine oranı bulundu ve pH değerlerine bağlı olarak reaksiyon verim değişimini 
gösteren grafikler hazırlandı. Her bir oran için üç ayrı deneme yapılarak ortalama değerler grafikte kullanıldı. TBA konsantrasyonunun reaksiyon hızına etkisini bulmak amaciyla ise; $0.01 \mathrm{M}, 0.1 \mathrm{M}$ ve 0.2 M olmak üzere üç ayrı konsantrasyonda TAB çözeltisi, her birinin pH sı 9 olacak şekilde hazırlandıktan sonra belirtilen zaman aralıklarında ölçümler yapılarak reaksiyon hız eğrileri çizildi. Bu çalışmalarda kullanılan iç standartlar tablo 2 de gösterilmiştir.

Kalibrasyon Eğrilerinin Çizilmesi: Alev iyonlaşma detektörü ile çalışılırken, $0.2 \mathrm{ml}, 50-250 \mu \mathrm{g} / \mathrm{ml}$ konsantrasyonlar arasında hazırlanmış barbitürat çözeltileri üzerine $0.4 \mathrm{ml}$ TAB çözeltisi $(0.5$ M, pH 9) ve $0.4 \mathrm{ml}$ fosfat tamponu ( $\mathrm{pH}$ 9) ilavesinden sonra 0.5 ml diklormetan ve $10 \mu 1$ PFBBr ilave edildi. Çalkalayıcıda 10 dakika karıştırıldı. Sulu faz ayrıldıktan sonra diklormetan fazı azot akımında uçuruldu, kalıntı $0.1 \mathrm{mg} / \mathrm{ml} \mathrm{n}$-tetrakozan veya $\mathrm{n}$-hekzakozan taşıyan $0.5 \mathrm{ml}$ n-hekzanda çözüldü. Bu çözeltiden $1 \mu$ l gaz kromatografa enjekte edilerek kalibrasyon eğrileri çizildi. Elektron yakalayan detektörle ise; yukarıdaki işlem aynen yürütülmekle birlikte son aşamada ECD için ortamda bulunması uygun olmayan PFBBr'ün fazlasını ortamdan uzaklaştırma amacıyla GYLLENHAAL ve arkadaşıarının (18) serbest yă asitlerinin türevlenmesinde uygulandıkları yöntem uygulandı. 1-10 $\mu \mathrm{g} / \mathrm{ml}$ arasındaki konsantrasyonlarda barbitürat ve her birinde $5 \mu \mathrm{g} / \mathrm{ml}$ Tablo 5 de gösterilen iç standart taşıan $0.2 \mathrm{ml}$ lik çözeltilerde reaksiyon yürütüldü. Ancak reaksiyon bitiminde PFBBr'ün fazlasını ortamdan uzaklaştırmak amacıyla $10 \mu 10.5 \quad \mathrm{M}$ hordenin sülfat ilave edildi. Hordenin'in PFBBr'le tümüyle reaksiyona girmesi için 15 dakika çalkalandı. Sulu faz ayrılıp, diklormetan fazı kuru bir tüpe aktarılarak oda sıcaklığında, azot akımında uçuruldu, kalıntı $2 \mathrm{ml}$ heptanda çözüldükten sonra $2 \mathrm{ml} \quad 0.1$ M sülfürik asitle ortamdan hordenin PFB türevini uzaklaştırmak amacıyla çalkalandı. Santrifüj edildikten sonra gaz kromatografa heptan fazından $1 \mu 1$ enjekte edildi.

SONUÇ ve TARTIŞMA

Alıkonma İndeksleri: Üzerinde çalıştı̆̆ımız barbitürat PFB türevlerinin ve barbitüratların SE-30 ve OV-17 durucu fazlarla hazırlanmış kolonlar için alıkonma indeksleri tablo 1 de gösterilmiştir. 
Analitik toksikoloji açısından yapılan ilaç tarama testlerinde, gaz kromatografisinde alıkonma indeksi sağlam bir veri olmakta, rölatif alıkonma süresi hesaplarına göre birbirine çok yakın alıkonma süresi olan veya elde standardı olmayan maddelerin tanınmasına da olanak vermektedir. Gaz kromatografik tanım amacıyla ilaçlar ve toksikolojik önemi olan maddeler için alıkonma indeksi listeleri yayınlanmıştır (19, 20). Alıkonma indeksi hesaplarını, barbitüratların PFB türevleri için karşılaştırılabilecek başka bir veri olmadı̆̆ından, uygun kolon ve iç standart seçiminde yararlanmak amacıyla yaptık. Tablo 1 de görüleceği gibi PFB türevlerinin alıkonma indeksleri seçilen kolonlarda barbitüratlarınkinden ve birbirinden yeterince farklıdır.

Ekstraktif Alkilleme Koşulları: Kimyasal maddelerin PFBBr' le ekstraktif alkillenmesi için reaksiyon koşulları çok farklı gösterilmiştir $(9,19,21,22,23,24)$. Bu çalışmaların bazılarında en fazla verimin alındı̆̆ le ekstraktif alkillenmesi konusunda tek yayın olan ve fenobarbitalle yapılmış çalışmada (9), koşulların reaksiyona etkisi belirtilmediğinden öncelikle verimin en fazla olduğu koşulları inceledik. Tablo 2 de verilen değerler reaksiyon süresi 10 dakika olarak tutulduğunda ve numuneler hemen gaz kromatografa verildiğinde bulunan sonuçlardır. Ancak 9 dan yüksek pH larda çalışıldığında ayırma işleminde bu süre aşılırsa verimin düştüğ̈ görülmüştür. Bu nedenle barbitüratların çoğu için maksimum verimin alındığı pH olan 9 çalışmalarda sürekli uygulanmıştır. Bu sonuç G YLLENHAAL ve arkadaşlarının (9) verdiği pH değerine uymaktadır. Ancak aynı araştırıcıların uyguladı̆̆ı gibi ortamda 0.1 M T B A bulunduğunda barbitüratların çoğunun ekstraktif alkillenmesi için sürenin çok uzadı̆̆ ${ }_{1}$ ve barbitalle, pentobarbital için bu konsantrasyonda $\mathrm{T} B \mathrm{~A}$ ile çalışıldı̆̆ında reaksiyon veriminin çok düşük olduğu görülmüştür. Bu çalışmalara ait sonuçlar Tablo 3 de görülmektedir TBA konsantrasyonunun düşük olması halinde çok uzun sürede bile reaksiyonun tamamlanamaması nedeni olarak G Y L LE N H A A L (25), PFBBr'ün bazik ortamda belli bir süre sonunda bozunarak pentafluorobenzil alkol ve bispentafluorobenzil etere dönüşmesini göstermiştir. Ortamda 0.2 M TBA bulunduğunda reaksiyon 10 dakika içinde tamamlanmaktadır. Bu nedenle ekstraktif alkilleme reaksiyonu pH 9 da ve 0.2 M TBA varlığında yürütülmüştür. Reaksiyon koşulları araştırılırken fazla sayıda değişkenin etkimemesi 
açısından alev iyonlaşma detektörü kullanılmıştır. Bu aşamada reaksiyon koşullarından etkilenmemeleri nedeniyle iç standart olarak alkanlar seçilmiştir. Daha sonraki aşamada elektron yakalayan detektörle çalışıldı ̆̆ında ise her bir barbitürat için alıkonma süresi uygun olan diğer bir barbitürat iç standart olarak kullanılmıştır. Detektörlerin, barbitürat PFB türevleri için doğrusal dinamik sınırı (LDR)

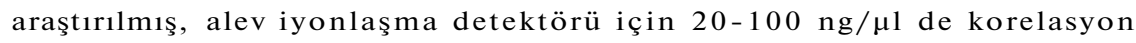
katsayısı r: 0.981-0.999 arasında ve elektron yakalayan detektör için

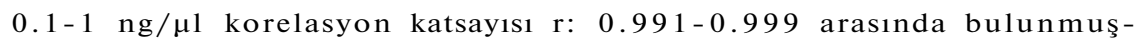
tur. Bu amaçla çizilen kalibrasyon denklemlerine ait sonuçlar tablo 4 ve 5 dedir.

Ekstraktif alkilleme işlemi tamamlandıktan sonra ortamda reaksiyona girmemiş PFBBr de bulunmaktadır. Özellikle ECD için zararlı olan ve detektörü kirleterek duyarlığının düşmesine neden olan bu reaktifi ortadan uzaklaştırmak amacıyla gaz kromatografa enjekte etmeden önce uçurma $(26,27)$, türevlemeden sonra ekstraksiyonla ayırma $(21,22)$ veya gaz kromatografa eklenen bir bölümde uçmayı sağlama (9) gibi çeşitli yöntemler geliştirilmiştir. Biz, kaynama noktası $174^{\circ} \mathrm{C}$ olan PFBBr'ün tamamının uçurulması çok zor olduğundan (9), gaz kromatografa eklenen uçurma bölümü alette değişiklik gerektirdiğinden ekstraksiyonla ayırma işleminde ise barbitürat PFB türevlerinin büyük bir kısmının PFBr ile aynı fazda kalması nedeniyle serbest yă asitleri ile ilgili çalışmada (18) kullanılan yöntemi uyguladık. Bu yöntemle PFBBr'ün fazlası hordeninle reaksiyona sokulmakta ve hordenin PFB türevi asitli ortamda sulu faza alınarak organik çözücüden ayrılmaktadır. Şekil 2-6 da da görülebileceği gibi bu yöntemle FBBFr'ün uzaklaştırılması ile elde edilen kromatogramlar yeterince temiz olmakta ve barbitürat türevleriyle, kullanılan reaktiflerin piklerinin karışması söz konusu olmamaktadır.

Yöntemimizle barbitüratların PFB türevleri için saptanabilen en düşük duyarlık 1 pikogram olarak bulunmuştur. Bu sonuç GYLLENHAAL ve arkadaşlarının (9) fenobarbital için verdiği değere uymaktadir. 
Tablo 1: Alıkonma İndeksleri

\begin{tabular}{|l|c|c|c|c|}
\hline \multirow{2}{*}{} & \multicolumn{2}{|c|}{ SE - 30 kolon } & \multicolumn{2}{c|}{ OV -17 kolon } \\
\cline { 2 - 5 } & Barbitürat & PFB türevi & Barbitürat & PFB türevi \\
\hline Allobarbital & 1600 & 2360 & 1915 & 2565 \\
Aprobarbital & 1620 & 2375 & 1935 & 2575 \\
Barbital & 1495 & 2275 & 1795 & 2475 \\
Butalbital & 1670 & 2390 & 1955 & 2570 \\
Butobarbital & 1660 & 2410 & 1970 & 2585 \\
Fenobarbital & 1950 & 2640 & 2405 & 2800 \\
Hekzobarbital & 1850 & 2245 & 2210 & 2530 \\
Heptabarbital & 2100 & 2745 & 2445 & 3025 \\
Pentobarbital & 1750 & 2470 & 2020 & 2665 \\
Sekobarbital & 1775 & 2495 & 2070 & 2695 \\
Siklobarbital & 1950 & 2685 & 2350 & 2935 \\
Vinbarbital & 1750 & 2500 & 2030 & 2700 \\
\hline
\end{tabular}

Tablo 2: pH Değişiminin Ekstraktif Alkilleme Verimine Etkisi (Kolon SE-30)

\begin{tabular}{|l|l|c|c|c|c|c|c|}
\hline \multirow{2}{*}{ Barbitürat } & \multirow{3}{*}{ İç Standart } & \multicolumn{3}{|c|}{ Pik yükseklikleri oranı (Numune /Çç standa } \\
\cline { 3 - 8 } & p H 6 & p H 8 & p H 9 & pH10 & p H11 & pH12 \\
\hline Allobarbital & n-Tetrakozan & 0.50 & 0.82 & 0.87 & 0.87 & 0.84 & 0.78 \\
Aprobarbital & n-Hekzakozan & 1.41 & 1.82 & 2.00 & 2.10 & 2.00 & 1.89 \\
Barbital & n-Tetrakozan & 0.60 & 1.00 & 1.29 & 1.29 & 1.30 & 1.30 \\
Butalbital & n-Hekzakozan & 0.02 & 0.78 & 1.56 & 1.50 & 1.50 & 1.50 \\
Butobarbital & n-Hekzakozan & 1.34 & 1.63 & 1.72 & 1.76 & 1.72 & 1.69 \\
Fenobarbital & n-Hekzakozan & 0.48 & 0.62 & 0.64 & 0.63 & 0.63 & 0.63 \\
Hekzobarbital & n-Tetrakozan & 0.40 & 0.70 & 0.73 & 0.71 & 0.70 & 0.70 \\
Heptabarbital & n-Hekzakozan & 0.31 & 0.55 & 0.62 & 0.59 & 0.58 & 0.58 \\
Pentobarbital & n-Hekzakozan & 0.02 & 0.76 & 1.56 & 1.50 & 1.50 & 1.46 \\
Sekobarbital & n-Hekzakozan & 0.77 & 0.95 & 1.14 & 1.08 & 1.06 & 1.04 \\
Siklobarbital & n-Hekzakozan & 0.52 & 0.66 & 0.79 & 0.78 & 0.75 & 0.73 \\
Vinbarbital & n-Hekzakozan & 0.50 & 1.10 & 1.29 & 1.35 & 1.32 & 1.25 \\
\hline
\end{tabular}

Tablo 3: TBA Konsantrasyonunun Barbitüratların Türevlerine hızına etkisi (Kolon SE-30)

\begin{tabular}{|c|c|c|c|c|c|c|c|c|c|c|c|c|}
\hline \multirow[b]{3}{*}{ Barbitürat } & \multicolumn{12}{|c|}{ Pik yüksekliği oranı (Numune/İç standart) } \\
\hline & \multicolumn{4}{|c|}{ Dakika } & \multicolumn{4}{|c|}{ Dakika } & \multicolumn{4}{|c|}{ Dakika } \\
\hline & 10 & 20 & 60 & 120 & 10 & 20 & 60 & 120 & 10 & 20 & 60 & 120 \\
\hline Allobarbital & .23 & 0.28 & 0.39 & 0.40 & 0.76 & 0.80 & 0.81 & 0.79 & 0.81 & 0.82 & 0.82 & 0.76 \\
\hline Aprobarb & 0.88 & 1.63 & 1.80 & 1.86 & 1.92 & 1.96 & 1.94 & 1.94 & 2.00 & 2.00 & 2.00 & 2.00 \\
\hline Barbital & 0.05 & 0.11 & 0.14 & 0.20 & 0.80 & 0.83 & 0.84 & 0.76 & 1.28 & 1.30 & 1.30 & 1.30 \\
\hline Butalbital & 0.85 & 1.03 & 1.25 & 1.25 & 1.10 & 1.23 & 1.37 & 1.30 & 1.40 & 1.42 & 1.42 & 1.38 \\
\hline Butobarbital & 1.00 & 1.10 & 1.20 & 1.20 & 1.56 & 1.60 & 1.60 & 1.60 & 1.78 & 1.80 & 1.80 & 1.80 \\
\hline Fenobarbital & 0.30 & 0.50 & 0.53 & 0.56 & 0.50 & 0.60 & 0.65 & 0.65 & 0.65 & 0.68 & 0.68 & 0.68 \\
\hline Hekzobarbital & 0.68 & 0.72 & 0.73 & 0.73 & 0.70 & 0.75 & 0.75 & 0.76 & 0.76 & 0.76 & 0.76 & 0.76 \\
\hline Heptabarbital & 0.35 & 0.48 & 0.52 & 0.53 & 0.50 & 0.58 & 0.60 & 0.61 & 0.60 & 0.63 & 0.63 & 0.63 \\
\hline Pentobarbital & 0.99 & 0.09 & 1.28 & 1.28 & 1.13 & 1.24 & 1.36 & 1.38 & 1.56 & 1.60 & 1.60 & 1.58 \\
\hline Sekobarbital & 0.63 & 0.87 & 0.96 & 0.96 & 0.88 & 1.00 & 1.06 & 1.07 & 1.10 & 1.13 & 1.13 & 1.13 \\
\hline Siklobarbital & 0.40 & 0.65 & 0.70 & 0.71 & 0.64 & 0.73 & 0.78 & 0.78 & 0.78 & 0.80 & 0.80 & 0.80 \\
\hline Vinbarbital & 0.67 & 0.76 & 0.94 & 0.96 & 1.36 & 1.38 & 1.38 & 1.38 & 1.38 & 1.39 & 1.39 & 1.39 \\
\hline
\end{tabular}


Tablo 4: Barbiturat PFB Türevlerinin Alev İyonlaşma Detektörü ile Kalibrasyon Denklemleri ve Korelasyon Katsayıları

\begin{tabular}{|l|l|l|l|}
\hline Barbiturat & İç standart & Kalibrasyon denkle & Korelasyon katsayısı \\
\hline Allobarbital & n-Tetrakozan & Y:0.020X-0.070 & r:0.996 \\
Aprobarbital & n-Hekzakozan & Y:0.034X-0.162 & r:0.982 \\
Barbital & n-Tetrakozan & Y:0.021X-0.088 & r:0.995 \\
Butalbital & n-Heksakozan & Y:0.020X-0.101 & r:0.993 \\
Butobarbital & n-Hekzakozan & Y:0.029X-0.235 & r:0.984 \\
Fenobarbital & n-Hekzokozan & Y:0.031X-0.059 & r:0.992 \\
Hekzobarbital & n-Tetrakozan & Y:0.016X-0.010 & r:0.999 \\
Heptabarbital & n-Hekzakozan & Y:0.013X-0.068 & r:0.997 \\
Pentobarbital & n-Hekzakozan & Y:0.026X-0.016 & r:0.999 \\
Sekobarbital & n-Hekzakozan & Y:0.020X-0.061 & r:0.999 \\
Siklobarbital & n-Hekzakozan & Y:0.015X-0.001 & r:0.999 \\
Vinbarbital & n-Hekzakozan & $Y: 0.025 X-0.004$ & r:0.999 \\
\hline
\end{tabular}

Tablo 5: Barbitürat PFB Türevlerinin Elektren Yakalayan Detektörle Kalibrasyon Denklemleri ve Korelasyon Katsayıları

\begin{tabular}{|l|l|l|l|}
\hline Barbitürat & İç standart & Kalibrasyon denklemi & Korelasyon katsayısı \\
\hline Allobarbital & Butobarbital & Y:1.85X-0.125 & r:0.991 \\
Aprobarbital & Vinbarbital & Y:3.02X-0.050 & r:0.999 \\
Barbital & Butobarbital & Y.-2.13X-0.007 & r:0.999 \\
Butalbital & Vinbarbital & Y:1.82X-0.083 & r:0.999 \\
Butobarbital & Vinbarbital & Y:2.39X-0.240 & r:0.997 \\
Fenobarbital & Heptabarbital & Y:2.79-X0.068 & r:0.999 \\
Hekzobarbital & Butobarbital & Y-.1.69X-0.028 & r:0.998 \\
Heptabarbital & Siklobarbital & Y:1.28X-0.009 & r:0.997 \\
Pentobarbital & Butobarbital & Y: $1.44 X-0.077$ & r:0.999 \\
Sekobarbital & Butobarbital & Y:.0.95X-0.002 & r:0.998 \\
Siklobarbital & Heptabarbital & $\mathrm{Y}: 3.10 X-0.148$ & r:0.998 \\
Vinbarbital & Butobarbital & $\mathrm{Y}: 1.20 X-0.008$ & r:0.999 \\
\hline
\end{tabular}

$$
\mathbf{R I}=\operatorname{100n} \frac{\mathbf{R d}(\text { Bilinmeyen) }-\mathbf{R d}(\mathbf{P z})}{\left.\operatorname{Rd} \mathbf{P}_{\mathrm{z}}+\mathbf{n}\right)-\operatorname{Rd}\left(\mathrm{P}_{\mathrm{z}}\right)}+\mathbf{1 0 0 z}
$$

Şekil 1. Alıkonma indeksi hesaplarında yararlanılan formül 


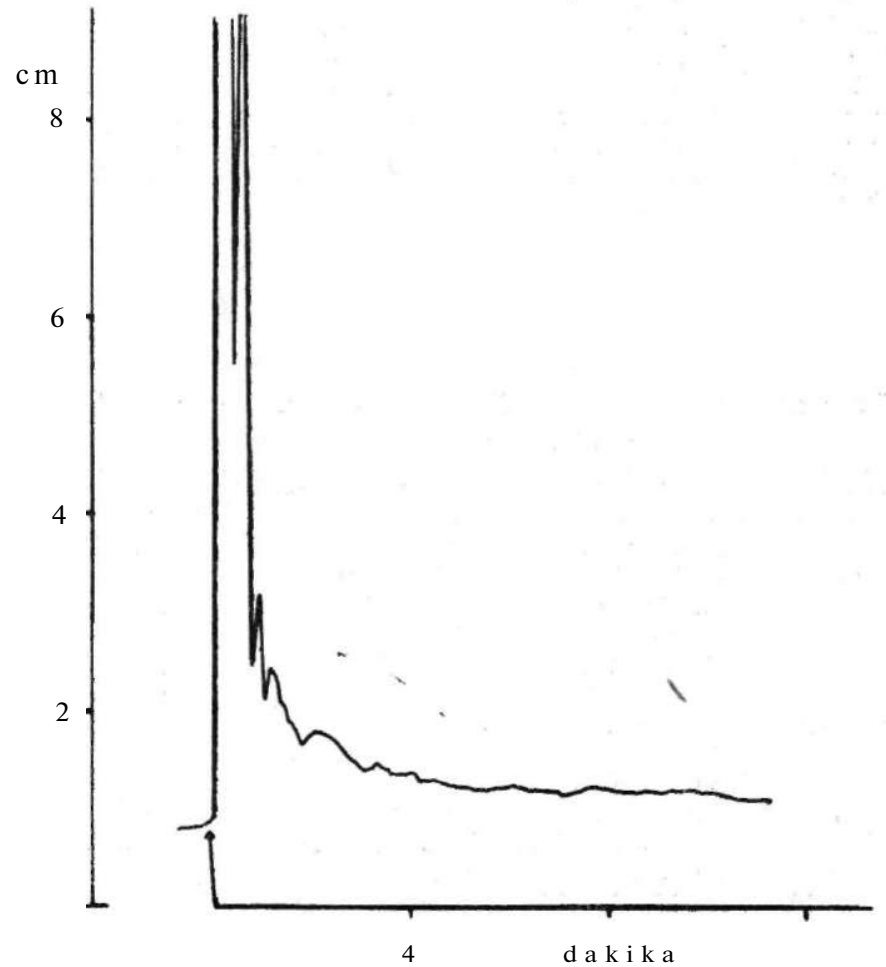

Şekil 2. Ekstraktif alkilleme işleminden sonra elde edilen boş kromatogram (Kolon: \% 3 SE-30, Kolon sicaklığı: $230^{\circ} \mathrm{C}$, detektör; ECD, attenuation; 216, 1 l numune). 


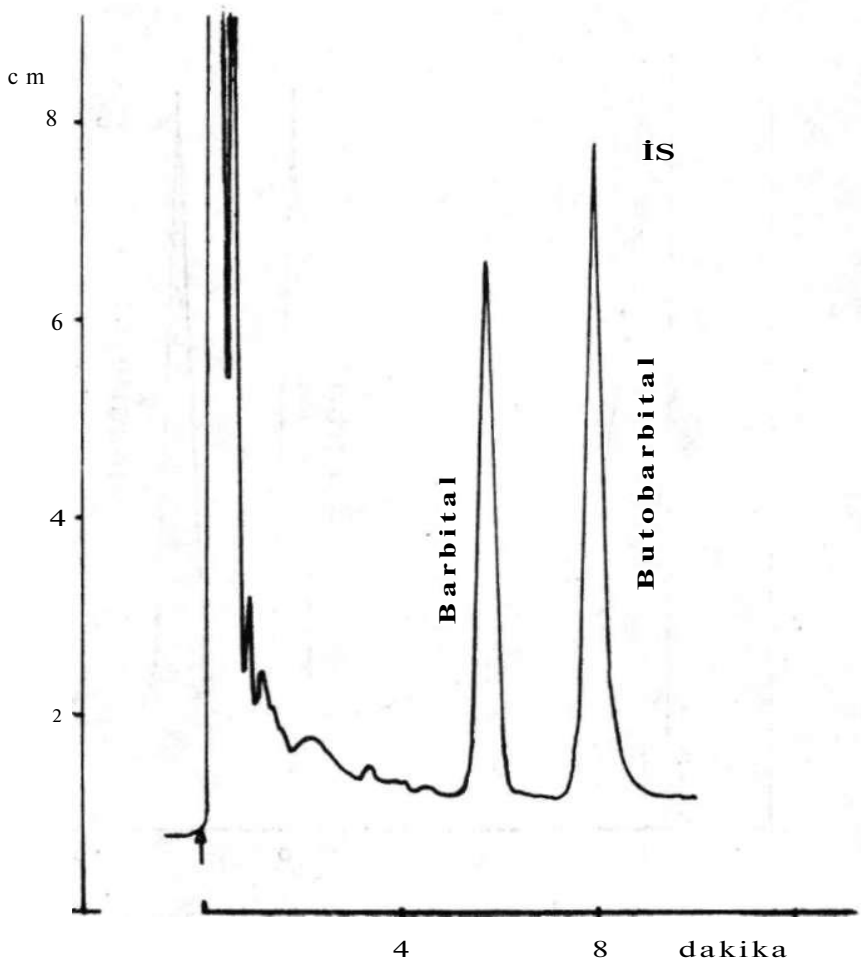

Şekil 3. Barbital PFB türevi gaz kromatogramı (Kolon: \% 3 SE-30, kolon sıcaklı̆̆ı: 230'C, detektör: ECD, attenuation: 216, $1 \mu 1$ numunede 100 pikogram barbital ve iç standart) 


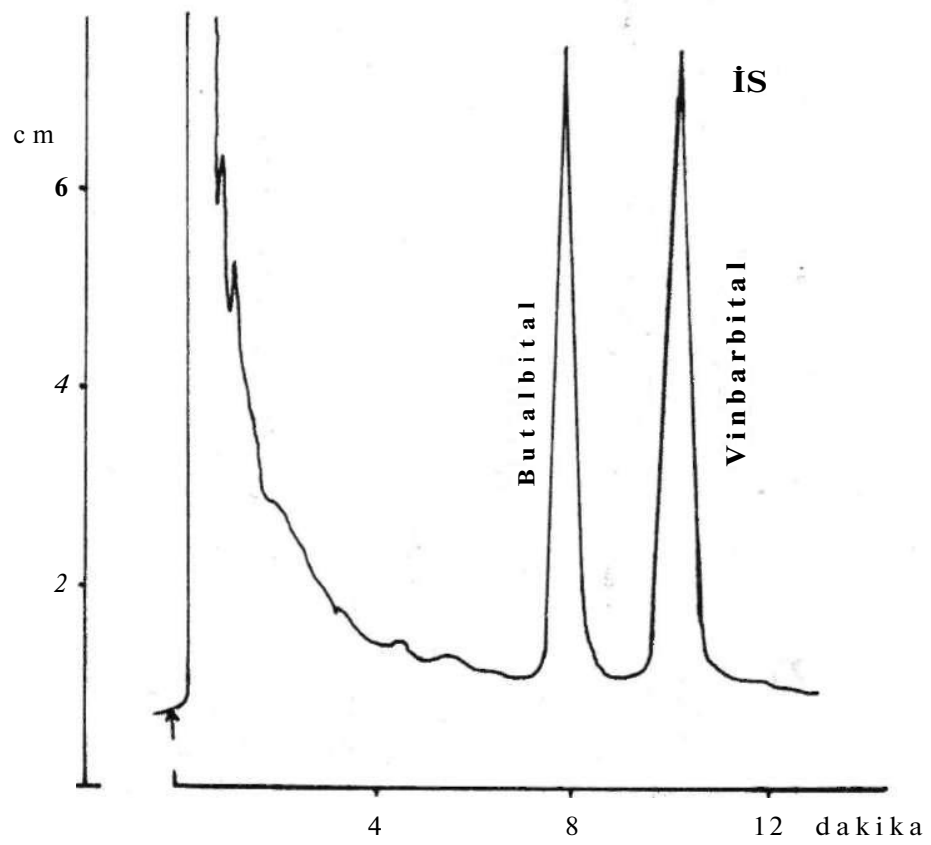

Şekil 4. Butalbital PFB türevi gaz kromatodramı (Kolon: \% 3 SE-30, kolon sıcaklığı: 230 C, detektör: ECD, attemıation: 216, $1 \mu$ l numunede 100 pikogram butalbital ve iç standart) 


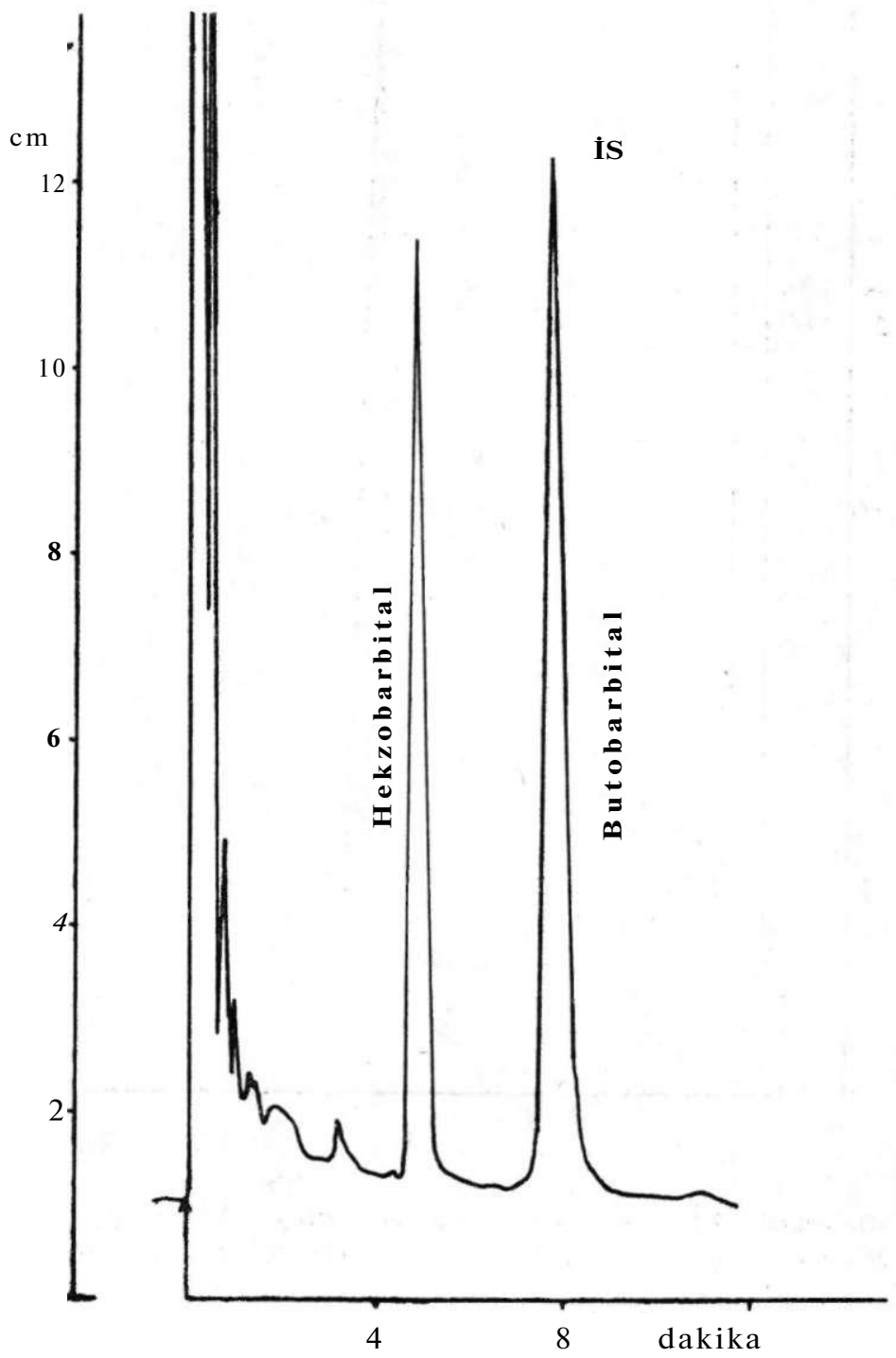

Şekil 5. Fenobarbital PFB türevi gaz kromatogramı (Kolon: \% 3 SE-30, kolon sıcaklığı: 245'C, detektör: ECD, attenuation: 216, $1 \mu$ l numunede 100 pikogram fenobarbital ve iç standart) 


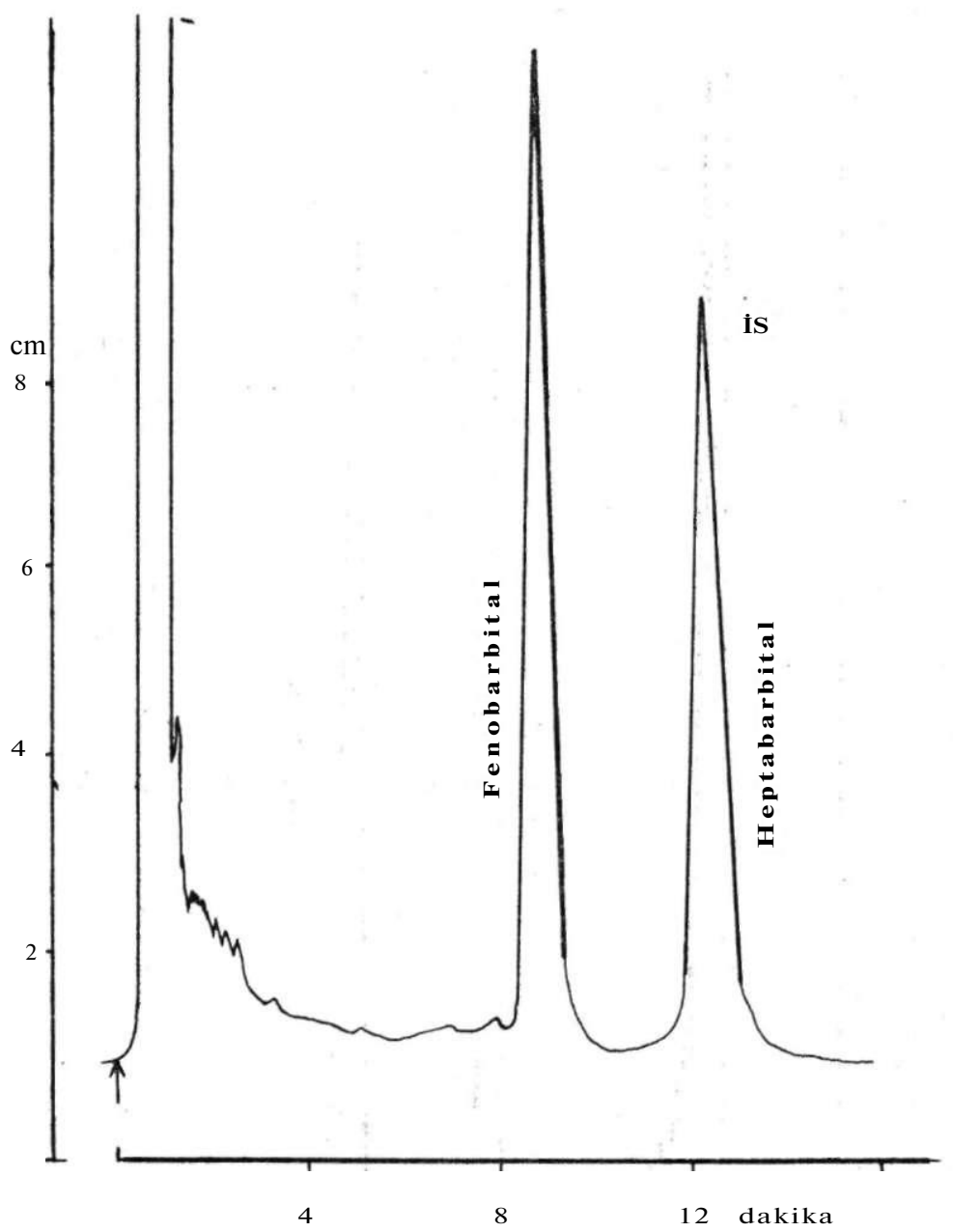

Şekil 6. Hekzobarbital PFB türevi gaz kromatogramı (Kolon: \% 3 SE-30, kolon sıcaklı̆̆ı: 230'C, detektör: ECD, attenuation: 216, $1 \mu$ l numunede 100 pikogram hekzobarbital ve iç standart) 


\section{LITERAT ÜR}

1- Gee D.J., The Poisoned Patient the Role of the Laboratory. Ciba Foundation Symposium 26, Elsevier Excerpta Medica, Amsterdam (1974)

2- Hine C.H., Hall. F.B., Türkei, H.W., Clin. Toxicol., 1 71-80 (1968)

3- Gudzinowicz B.J., Gas Chromatographic Analysis of Drugs and Pesticides. Marcel Dekker Inc., New York (1967)

4- Pillai D.N. Dilli, S., J. Chromatogr., 220 253-274 (1981)

5- McCaUum N.K., Armstrong R.J. J. Chromatogr. 78 303-307 (1973)

6- Wilkinson, G.R., Anal Letters, 3 289-298 (1970)

7- Nicholson, J.D., The Analyst, 103 1-27 (1978)

8- Walle T., J. Chromatogr., 114 345-350 (1975)

9- Gyllenhaal, O., Brötell. H., Sandgren, B., J. Chromatogr., 122 471:477 (1976)

10- Brandström, A., Junggren, U., Acta Chem. Scand., 23 2204-2205 (1969)

11- Hulshoff, A., Forch, A. D., J. Chromatogr. 120 275-311 (1981)

12- Jonkman, J.H.G., Pharm. Weekbl. 110 649-655 (1975)

13-Vessman, J., Johansson, M., Magnusson, P., Strömberg, S., Anal. Chem. 49 1545-1549 (1977)

14- Mordgren, T., Sjöden, E.K. Acta Pharm. Suec., 15 241-254 (1978)

15- Jansson, S.O., Nordgren, T., Schill, G., Acta Pharm. Suec, 14 435-450 (1977)

16- Fagerlund, C, Hartvig, P., Lindstrom, B.J. Chromatogr., 168 107-116 (1979 1

17- Leach, H., Gas Chromatography. Isolation of Drugs. V. 2 Ed. Clarke, E.G.C., The Pharmaceutical Press, London (1975

18- Gyllenhaal, O., Brötell H. Hartvig P. J. Chromatogr., 129 295-302 (1976)

19- Berninger, H. Möller, M.R., Arch. Toxicol., 37: 295-305 (1977)

20- Moffat, A.C., J. Chromatogr. 113 69-95 (1975)

21 - Arbin, A., Edlund, P.O., Acta Pharm. Suec, 12 119-126 (1975)

22- Brötell. H., Ehrsson, H., Gyllenhaal, Q., J. Chromatogr., 78 293-301 (1973)

23- Cole, W.J., Parkhouse, J.Y.Y., J. Chromatogr., 136 409-416 (1977)

24- Grevig, J.E., Jonkman, J.H.G., Fiks, F., de Zeeuw, R., van Bork, L.E., Orie, N. G.M., J. Chromatogr., 142 611-619 (1977)

25- Gyllenhal. O., J, Chromatogr., 153 517-520 (1978)

26- Kaiser, D.G., Shaw, S.R., Vangiessen, G.J., J. Pharm. Sci. 63 567-570 (19SS)

27- Wickramasinghe, J.A.F., Morosowich, W., Hamlin, W.E., Shaw, W.E.,J.Pharm. Sci, 62 1428-1431 1973 